\title{
Cine Phase-Contrast MR Images Failed to Predict Clinical Outcome Following ETV
}

\author{
Xiao Di, M. Ragab, Mark G. Luciano
}

\begin{abstract}
Background: To predict success of endoscopic third ventriculostomy (ETV) in patients with obstructive hydrocephalus, we evaluated pre- and post- operative phase-contrast cine magnetic resonance images (PC MRI) on cerebrospinal fluid (CSF), cine flow in basal cisterns around the brain stem, and cervical medullar junction (CMJ) retrospectively. Methods: The study involved 102 patients with mean age of $36.74 \pm 23.25$, and $\mathrm{F} / \mathrm{M}=1.55$. All patients had PC MRI taken both pre- and post-operatively. A dynamic MRI video of PC MRI was reviewed at sagittal, axial, and coronal sections to determine cistern flows around the brain stem and CMJ. For quantitative analysis, quadrants were divided around midbrain axially to evaluate interpeduncular, quadrageminal, and ambient cisterns of both sides using scores of 0 to 60 . Pre- and post- pontine and CMJ flows were shown in sagittal view and scored 0 to 20 , and lateral cerebellopontine cisterns of both sides were measured on coronal image and scored 0 to 20. Results: No significant difference in CSF flow was seen from three individual views and total cine score, or between ETV success and failure groups by multivariate analysis of variance. Kaplan-Meier Analysis and Spearman's Correlation Test produced no relationship between MRI cine flow scores and interval period after surgery to ETV failure. Conclusion: PC MRI cine flow failed to demonstrate significant differences between successful and failed ETV groups. This indicates in addition to achieving an adequate fenestration, CSF pathways beyond the basal cisterns around the brain stem and CMJ may play an essential role in achieving ETV success.
\end{abstract}

RÉSUMÉ: Des images ciné en contraste de phase n'ont pas prédit l'issue clinique après une ventriculostomie endoscopique du troisième ventricule. Contexte : Nous avons évalué rétrospectivement les images ciné du liquide céphalorachidien (LCR), du flux ciné dans les citernes interpédonculaires autour du tronc cérébral et à la jonction médullaire cervicale (JMC), obtenues par résonance magnétique en contraste de phase (IRM $\mathrm{CP})$ avant et après la chirurgie, afin d'anticiper le succès de la ventriculostomie endoscopique du troisième ventricule (VET) chez des patients atteints d'hydrocéphalie obstructive. Méthodes : Cent deux patients, dont l'âge moyen était de 36,74 ans $\pm 23,25$ et le ratio F/M de 1,55, ont participé à l'étude. Tous les patients ont subi une IRM CP avant et après la chirurgie. Une vidéo IRM dynamique de l'IRM CP a été révisée au niveau des sections sagittales, axiales et coronales pour déterminer les flux cisternaux autour du tronc cérébral et à la JMC. Pour les fins de l'analyse quantitative, des quadrants ont été établis autour de l'axe du mésencéphale pour évaluer les citernes interpédonculaires, les régions quadrigéminales et ambientes des deux côtés au moyen d'un score de 0 à 60 . Les flux pré et post pontins et les flux au niveau de la JMC étaient visualisés en incidence sagittale et cotés de 0 à 20 et les citernes latérales cérébellopontines des deux côtés ont été mesurées sur des images coronales cotées de 0 à 20 . Résultats : Aucune différence significative du flux du LCR n'a été observée sur trois clichés individuels et l'analyse de variance multivariée n'a décelé aucune différence significative du score ciné total ou entre les groupes dont la VET a été un succès ou un échec. Le test de Kaplan-Meier et le test de corrélation de Spearman n'ont pas montré de relation entre les scores du flux au ciné IRM et l'intervalle entre la chirurgie ou entre les scores et l'échec de la VET. Conclusion : Le ciné IRM CP du flux n'a pas montré de différence significative entre le groupe dont la VET a été un succès et le groupe dont la VET a été un échec. Ceci indique qu'en plus de réussir à établir une fenestration adéquate, les voies du LCR au-delà des citernes interpédonculaires autour du tronc cérébral et à la JMC pourraient jouer un rôle essentiel dans le succès de la VET.

Can. J. Neurol. Sci. 2009; 36: 643-647

Endoscopic third ventriculostomy (ETV) has been a popular surgical option for obstructive hydrocephalus (OHCP) in recent decades. ${ }^{1-3}$ A number of studies worldwide have reported favorable outcomes; ${ }^{4-6}$ however, in some cases, ETV fails to resolve symptoms, even when it is technically successful with adequate patent stoma and fenestrated Lillequist membrane. ${ }^{7-11}$ It has been hypothesized that patients might suffer from hydrocephalus caused by other obstructive membranes or by fibrosis in the subarachnoid space, especially around basal cisterns. Cine phase-contrast magnetic resonance imaging (PC $\mathrm{MR}$ ) has been utilized as a method of distinguishing between communicating and noncommunicating hydrocephalus and detecting postoperative fenestration patency after ETV.,10,12-14 In this retrospective study, we reviewed the pre- and

From the Department of Neurological Surgery, Neurological Institute, Cleveland Clinic, Cleveland, Ohio, USA.

Received February 23, 2009. Final Revisions Submitted March 31, 2009. Correspondence to: Xiao Di, Department of Neurological Surgery, Neurological Institute, Cleveland Clinic, 9500 Euclid Avenue, S90, Cleveland, Ohio, 44195, USA. 
postoperative cine PC MRI and outcomes to identify cine flow in basal cisterns and around cervical medullary junction (CMJ). Because of the high success rate of ETV, there are fewer patients in the failed group than in the successful one. This study assembled the largest series of patients with pre- and post- ETV PC MRI data, analyzed them by cine score at axial, sagittal, and coronal views in basal cisterns and CMJ, and then calculated total percentage of cine flow from those three scores.

\section{Patients And Methods}

The study population was 102 patients (62 female and 40 male) with a mean age at study entry of 36.7 years (range 0.4-90 years) who have pre- and post- ETV PC MRI. All patients underwent ETV for obstructive hydrocephalus (OHCP) at the Cleveland Clinic between August 1995 and February 2003. Obstructive hydrocephalus was defined as ventriculomegaly with obstruction between the aqueduct and fourth ventricle outlet as shown on preoperative anatomic MRIs. Sixty-four cases of idiopathic aqueductal stenosis (IAS) were diagnosed when the obstruction had no clear etiology and when the fourth ventricle was relatively small despite enlarged lateral and/or third ventricles. Among remaining patients, OHCP was diagnosed with tectal (8), pineal (6), intraventricular (4), and posterior fossa (5) tumors; Chiari malformation type I (6); myelomeningocele (6); and congenital aqueductal stenosis (3).

All patients were followed through July 2003 (median follow-up, 24.9 months; range, 3 to 73 months). Endoscopic third ventriculostomy was considered to have failed if the patient developed any condition that required further surgical cerebrospinal fluid (CSF) diversion. The interval to ETV failure was calculated from the date of ETV to the date of further surgical CSF diversion. Out of the 102 patients, 26 (25.49\%) required further surgical CSF diversion during the study period. Cine PC MRI was performed before ETV, on the second day, and at one year and two years after ETV with the exception of patients who underwent the cine PC MR when symptoms recurred. Cine PC MRI was performed in three axes (axial, sagittal, and coronal) to avoid any false-negative findings resulting from a slice deviation. Anatomic MRI was also obtained to follow the ventricular size change. Presence of both a systolic and diastolic flow on video cine PC MRI measurements was qualified for the existence of regional CSF flow.

Utilizing a simple mathematic calculation and percentage, a total of 100 points were added from 5, 10, 20 and 30 assigned to the three views of the MRI with cine flow including axial, sagital, and coronal views. Quadrants were divided around midbrain to evaluate the interpeduncular, quadrageminal, and ambient cisterns, which were assigned 15, 15, and 30 for both sides on axial view, respectively (Figure 1a). Pre- and postpontine cisterns around $\mathrm{CMJ}$ were recorded on the sagittal view with the assigned scores 10 and 10 (Figure 1b), and lateral cerebellopontine and cerebellomedullary cisterns around CMJ were assigned 10 for each side on the coronal image with scores from 0 to 20 (Figure 1c).

Two individual observers blindly reviewed data from raw cine scores recorded on the three views including the axial, sagital, and coronal imagings. The two observers' scores were averaged, and then the scores from the three views were added to calculate the patient's final score, which was translated into a

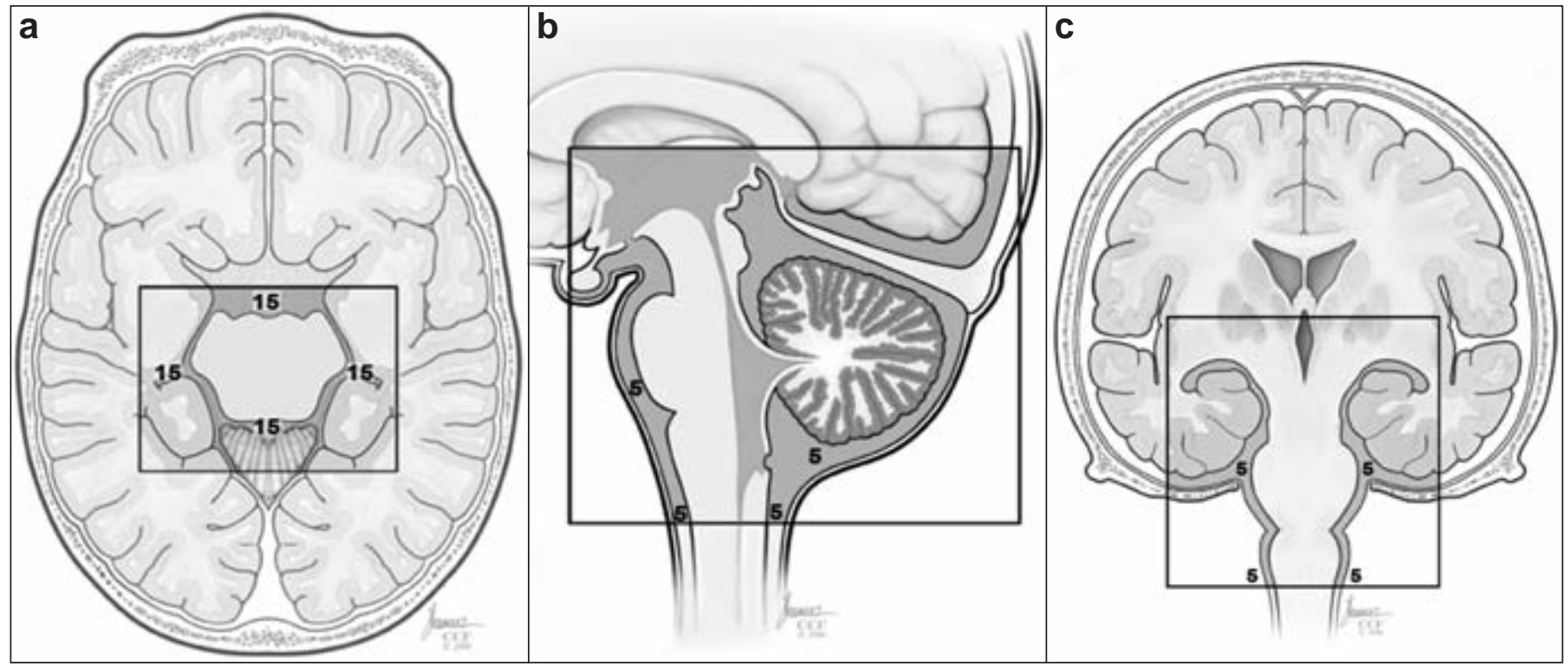

Figure 1: Cartoons showed divisions with score recordings. (1a) Axial: around midbrain to evaluate the interpeduncular, quadrageminal and ambient cisterns of the both sides with scores 0 to 60. (1b) Sagittal: Pre-and post-pontine around CMJ flows shown with scores from 0 to 20. (1c) Coronal: Lateral cerebellopontine and cerebellomedullar cisterns of both sides with scores from 0 to 20. 


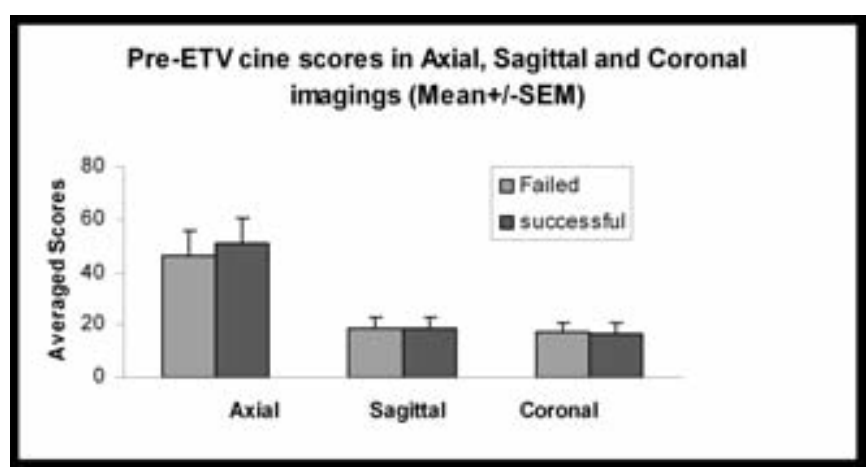

Figure 2: Pre-ETV cine scores in Axial, Sagittal and Coronal imagings (Mean+/-SEM).

percentage. The percentage of cine flow calculated represented total PC MRI measurement around basal cisterns and CMJ for a patient at a designated time. Data in this series contained the preETV and post-ETV immediately following surgery and at one year and two years afterward.

\section{Statistical Analysis}

Phase-contrast cine MRI scores around basal cisterns, CMJ, and the percentage of cine flow were tested between ETV successful and failed patient groups by multivariate analysis of variance. The relationship between the interval to ETV failure and the PC MRI cine scores and its percentage of cine flow were assessed with a Spearman's correlation test. Kaplan-Meier estimates of time to failure were compared in the low and high flow groups with the log rank test. The level of statistical significance for all tests was set at $\mathrm{p}<0.05$.

\section{Results}

There were no significant differences in any cine scores of axial, sagittal, and coronal sections or in the percentage of total cine flow between successful and failed groups before (Figures 2

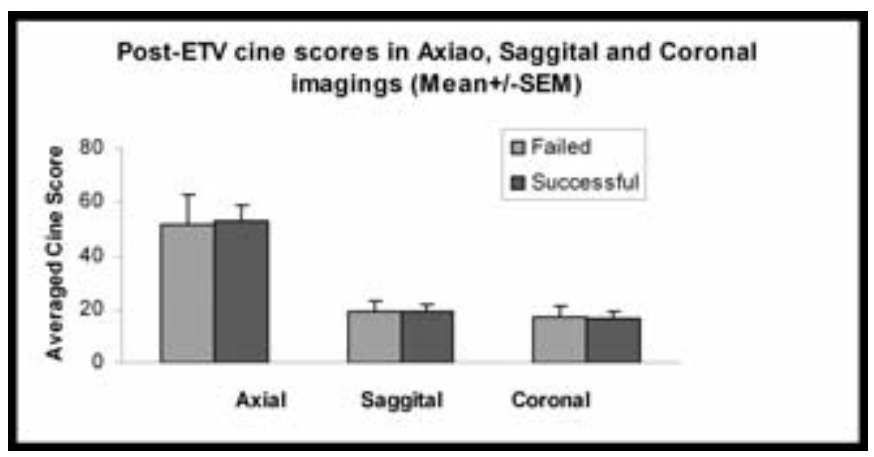

Figure 4: Post-ETV cine scores in Axial, Saggital and Coronal imagings $($ Mean+/-SEM).

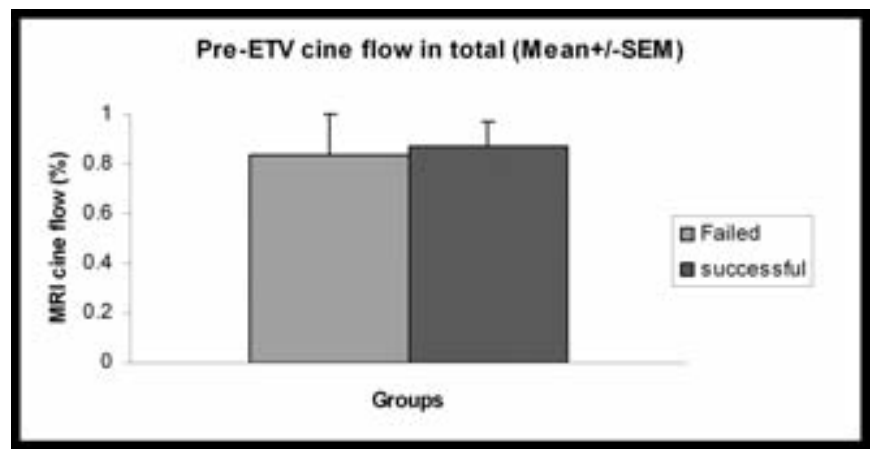

Figure 3: Pre-ETV cine flow in total (Mean+/-SEM).

\& 3) and after ETV (Figures 4 \& 5). There were trends of increases in both the cine score of axial section and total percentage of cine flow both before and after. No significant difference between failed and successful groups was found at either the single cine score and percentage of total cine flow before and after ETV (Figures 6 \& 7).

The median time interval from the initial ETV to re-operation was nine months (range, 0.25 to 55 months) in the failed group. Eight patients in this series $(30.8 \%)$ had another operation within 30 days because they had headache or lethargy that did not resolve. Another 18 patients had an additional operation later: 12 patients $(66.7 \%)$ within one year, 5 patients $(27.8 \%)$ between one and two years post-surgery, and 1 patient at about four years after. From 11 patients $(42.3 \%)$ having a history of previous shunt implantation, 9 patients had a re-do ETV, and eventually 6 of them were shunted. No statistical relationship was found by the Spearman Rank Test between any cine score of the three views and its total percentage of cine flow of PC MRI in the basal cistern and $\mathrm{CMJ}$, or in the interval to re-operation following ETV. In addition Kaplan-Meier Analysis produced no significant finding between the low and high groups of cine score and percentage of cine flow.

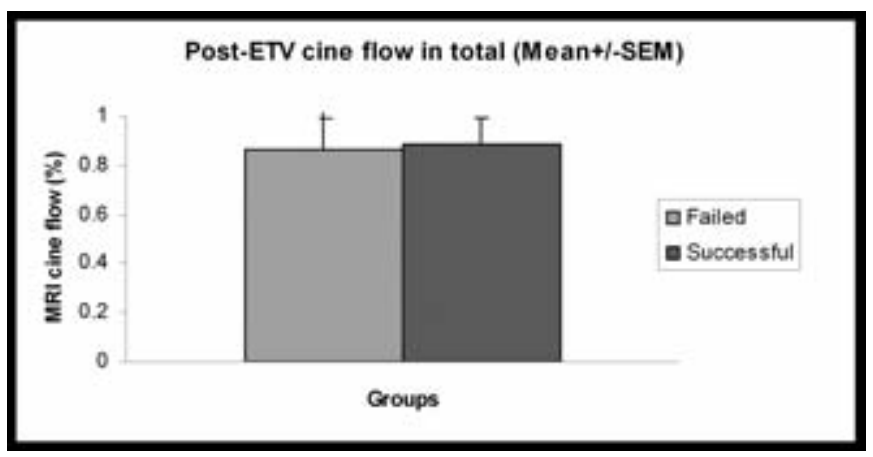

Figure 5: Post-ETV cine flow in total (Mean+/-SEM). 


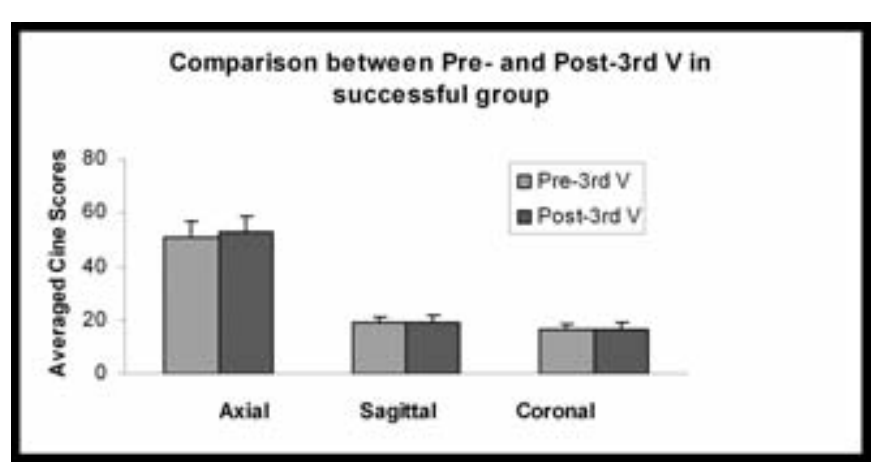

Figure 6: Comparison between Pre- and Post-3rd V in successful group.

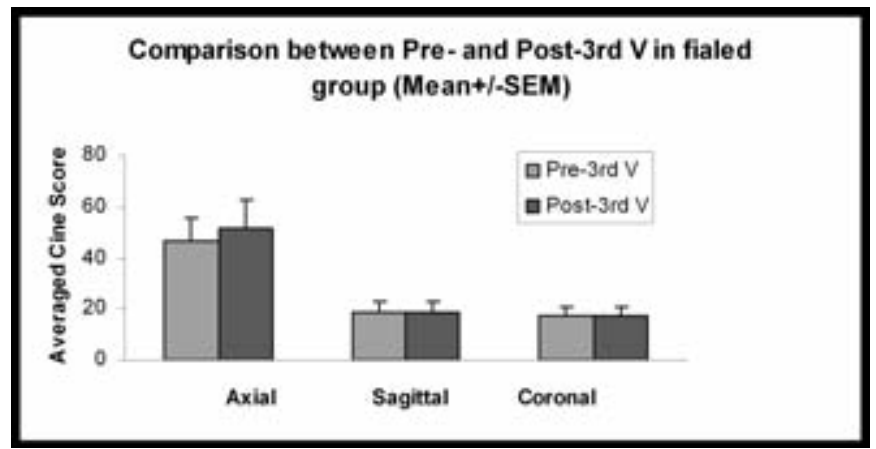

Figure 7: Comparison between Pre- and Post-3rd V in failed group (Mean+/-SEM).

subarachnoid space. No significant increase in PC MRI cine flow seen in both the failed and successful groups corresponds to the speculation that CSF from the third ventricle spreads rapidly upwards to supratentorial subarachnoid space. There was more of a trend toward a larger increase in cine score of axial view in the successful group than in the failed group in preoperative MRI, but it was not significant. This suggests that the wide open basal cisterns could play a fundamental role in ETV success that was not demonstrated in this series.

However, the better pre-ETV cine scores and even total percentage of cine flow did not indicate the ideal candidates for ETV and also did not correlate with ETV outcome, which could indicate that the basal cisterns and CMJ are not as vital in this process. The final destination of CSF circulation is via venous absorption through granular villi, lymphatic channels, and/or perivascular compartments, recently illustrated by a number of animal studies. These current findings suggest that there was a loss of multiple hemispheric absorption pathways including arachnoid villi, lymphatic system, microvascular system and/or nerve roots along the olfactory nerve and the nasolacrimal duct, and spinal canal, etc. beyond the basal cisterns and CMJ.21-23 Those CSF absorption devices declined possibly due to lengthy intracranial hypertension, especially in the patient with CSF diversion. ${ }^{17,20,24}$ In other words, the previous ETV-treated OHCP might already coexist with "communicating HCP" due to the decrease in CSF absorption even before initial ETV.

In the current study, 11 patients $(42.3 \%)$ from the 26 ETVfailed patients had a history of previous shunt implantations. Additionally, re-do ETV was performed on 9 patients in the initially failed group, six of whom eventually ended up with shunting, even though the patent fenestration was ensured. Interestingly, 16 patients $(61.5 \%)$ in the failed-ETV group showed PC MRI flow through the stoma in the floor of the third ventricle at the time of clinical failure and the further surgical intervention. But neither the Spearman Rank Test or KaplanMeier Analysis showed a significant relationship between the cine scores and total percentage of cine flow with the survival rate or interval to failed ETV. The hypothesis that deteriorated CSF absorption function due to the lengthy IC-HTN and CSF diversion may be responsible for the failure of ETV- treated $\mathrm{OHCP}$ is consistent with recent findings that prior CSF shunting 
increases the risk of ETV failure in the treatment of obstructive hydrocephalus in adults. ${ }^{24}$ Rekate reported that five of six adults with longstanding overt ventriculomegaly had free flow of cerebrospinal fluid into the basal cisterns following ETV and remained symptomatic, requiring further treatment. Four patients received ventriculoperitoneal shunts, and one underwent venous stenting for high intracranial pressure after successful ETV, which Rekate believed may have been caused by increased venous sinus pressure. ${ }^{25}$ The hypothesis of decreased brain CSF absorption by granular villi and venous pressure was supported by a hydrostatic test, showing mobility of the stoma as an important predictor of ETV success provided that there is no obstruction at the level of the arachnoid granulations or venous outflow. ${ }^{26}$

Further study is needed to investigate the hypothesis that the obliteration of cerebrospinal fluid pathways, the deteriorated CSF absorption, or increased venous pressure can be responsible for the failure of ETV-treated OHCP.

In this study, PC MRI cine flow scores around basal cisterns and CMJ failed to demonstrate either any significant difference between successful and failed groups or correlation with patients' outcome of ETV. The weakened CSF pathways beyond basal cisterns may be considered as more significantly problematic for failed ETV.

\section{ACKNOWLEDGEMENTS}

The author thank Ms. Christine Moore and Mr. Joe Kanasz for their assistance with the preparation and illustration of this manuscript.

\section{REFERENCES}

1. de Ribaupierre S, Rilliet B, Vernet O, Regli L, Villemure JG. Third ventriculostomy vs ventriculoperitoneal shunt in pediatric obstructive hydrocephalus: results from a Swiss series and literature review. Childs Nerv Syst. 2007;23(5):527-33.

2. Hoffmann KT, Lehmann TN, Baumann C, Felix R. CSF flow imaging in the management of third ventriculostomy with a reversed fast imaging with steady-state precession sequence. Eur Radiol. 2003;13(6):1432-7.

3. Maeder P, Gudinchet F, Meuli R, Fankhauser H. Dynamic MRI of cerebrospinal fluid flow in endoscopic percutaneous ventriculostomy. Br J Neurosurg. 1998;12:18-22.

4. Goumnerova LC, Frim DM. Treatment of hydrocephalus with third ventriculocisternostomy: outcome and CSF flow patterns. Pediatr Neurosurg. 1997;27(3):149-52.

5. Kim SK, Wang KC, Cho BK. Surgical outcome of pediatric hydrocephalus treated by endoscopic III ventriculostomy: prognostic factors and interpretation of postoperative neuroimaging. Childs Nerv Syst. 2000;16:161-9.

6. Yamamoto M, Oka K, Ikeda K, Tomonaga M. Percutaneous flexible neuroendoscopic ventriculostomy in patients with shunt malfunction as an alternative procedure to shunt revision. Surg Neurol. 1994;42:218-23.

7. Bargallo N, Olondo L, Garcia AI, Capurro S, Carol L, Rumia J. Functional analysis of third ventriculostomy patency by quantification of CSF stroke volume by using cine phasecontrast MR imaging. AJNR Am J Neuroradiol. 2005;26(10): 2514-21.

8. Fukuhara T, Luciano MG, Kowalski RJ. Clinical features of third ventriculostomy failures classified by fenestration patency. Surg Neurol. 2002;58(2):102-10.

9. Fukuhara T, Vorster SJ, Luciano MG. Risk factors for failure of endoscopic third ventriculostomy for obstructive hydrocephalus. Neurosurgery. 2000;46(5):1100-9; discussion 1109-11.
10. Fukuhara T, Vorster SJ, Ruggieri P, Luciano MG. Third ventriculostomy patency: comparison of findings at cine phasecontrast MR imaging and at direct exploration. AJNR Am J Neuroradiol. 1999;20(8):1560-6.

11. Lev S, Bhadelia RA, Estin D, Heilman CB, Wolpert SM. Functional analysis of third ventriculostomy patency with phase-contrast MRI velocity measurements. Neuroradiology. 1997;39:175-9.

12. Connor SE, O'Gorman R, Summers P, Simmons A, Moore EM, Chandler C, et al. SPAMM, cine phase contrast imaging and fast spin-echo T2-weighted imaging in the study of intracranial cerebrospinal fluid (CSF) flow. Clin Radiol. 2001;56(9):763-72.

13. Missir O, Dormont D, Pierot L. MR visualization of CSF flow through a ventriculo-cisternostomy. Neuroradiology. 1989;31: 93-4.

14. Rovira A, Capellades J, Grive E, Poca MA, Pedraza S, Sauquillo J, et al. Spontaneous ventriculostomy: report of three cases revealed by flow-sensitive phase-contrast cine MR imaging. AJNR Am J Neuroradiol. 1999;20(9):1647-52.

15. Carpentier A, Brunelle F, Philippon J, Clemenceau S. Obstruction of Magendie's and Luschka's foramina. Cine-MRI, aetiology and pathogenesis. Acta Neurochir (Wien). 2001;143(5):517-21.

16. Jallo GI, Kothbauer KF, Abbott IR. Endoscopic third ventriculostomy. Neurosurg Focus. 2005;19(6):E11.

17. Cinalli G, Sainte-Rose C, Chumas P, Zerah M, Brunelle F, Lot G, et al. Failure of third ventriculostomy in the treatment of aqueductal stenosis in children. J Neurosurg. 1999;90(3):448-54.

18. Suehiro T, Inamura T, Natori Y, Sasaki M, Fukui M. Successful neuroendoscopic third ventriculostomy for hydrocephalus and syringomyelia associated with fourth ventricle outlet obstruction. Case report. J Neurosurg. 2000;93(2):326-9.

19. Teo C, Jones R. Management of hydrocephalus by endoscopic third ventriculostomy in patients with myelomeningocele. Pediatr Neurosurg. 1996;25:57-63.

20. Kehler U, Gliemroth J. Extraventricular intracisternal obstructive hydrocephalus - a hypothesis to explain successful 3rd ventriculostomy in communicating hydrocephalus. Pediatr Neurosurg. 2003;38(2):98-101.

21. Johnston M, Armstrong D, Koh L. Possible role of the cavernous sinus veins in cerebrospinal fluid absorption. Cerebrospinal Fluid Res. 2007;16;4(1):3.

22. Koh L, Zakharov A, Nagra G, Armstrong D, Friendship R, Johnston M. Development of cerebrospinal fluid absorption sites in the pig and rat: connections between the subarachnoid space and lymphatic vessels in the olfactory turbinates. Anat Embryol (Berl). 2006;211(4):335-44

23. Nagra G, Koh L, Zakharov A, Armstrong D, Johnston M. Quantification of cerebrospinal fluid transport across the crib riform plate into lymphatics in rats. Am J Physiol Regul Integr Comp Physiol. 2006;291(5):R1383-9.

24. Woodworth G, McGirt MJ, Thomas G, Williams MA, Rigamonti D. Prior CSF shunting increases the risk of endoscopic third ventriculostomy failure in the treatment of obstructive hydrocephalus in adults. Neurol Res. 2007;29(1):27-31.

25. Rekate HL. Longstanding overt ventriculomegaly in adults: pitfalls in treatment with endoscopic third ventriculostomy. Neurosurg Focus. 2007;15;22(4):E6

26. Kamel MH, Kelleher M, Aquilina K, Lim C, Caird J, Kaar G. Use of a simple intraoperative hydrostatic pressure test to assess the relationship between mobility of the ventricular stoma and success of third ventriculostomy. J Neurosurg. 2005;103(5): 848-52. 